natural dam hazard could cause a massive release of lethal $\mathrm{CO}_{2}$ from the lake waters or underlying sediments. We recognize this hazard and feel that additional study of the factors controlling gas accumulation and release is needed. But our inspection of the dam has convinced us that it is not safe and that there is a strong possibility of failure within the not-too-distant future. The potential loss of life from failure of the dam is much greater than that from another gas release because of the current downstream population distribution. Measures to warn threatened populations are urgently needed. Action to remove the flooding hazard by lowering the lake level should proceed as soon as engineering studies provide viable options, including a method of controlled degassing of $\mathrm{CO}_{2}$ from the lake.

JoHn P. LockwOOD

US Geological Survey,

Hawaiian Volcano Observatory,

Hawaii 96718, USA

US Geological Survey,

Robert L. Schuster

Branch of Geologic Risk Assessment,

Denver, Colorado 80225, USA

1. Dalrymple, G. B. \& Lockwood, J. P. Natural Hazards 3 , 373-378 (1990)

2. Lockwood, J. P., Costa, J. E., Tuttle, M. L., Nni, J. \& Tebor, S. G. Bull. Volcan. 50, 340-349 (1988).

3. van Zyl, D. \& Harr, M. E. Proc. 10th Int. Conf. Soil Mechanics

Foundn Engng, Stockholm, 1, 309 (1981).

4. Freeth, S. J. et al. Nature 348, 201 (1990).

\section{Hominid dental development}

SIR - Mann, Monge and Lampl have disputed $^{1}$ the findings of two previous studies ${ }^{2,3}$ that claim a short period of dental development in hominids, but they misunderstand the arguments regarding tooth development. These new studies rely on endogenous circadian and circaseptan rhythms that operate during tooth development. Perikymata are secondary manifestations, on the tooth surface, of an internal 7-9 day cyclical variation in enamel secretion, which produces striae. Secretion slows at the enamel surface, either abruptly with striae terminating in troughs (demarcating perikymata, part $a$ of figure), or progressively, resulting in a smooth enamel surface (see part $b$ of figure). It is unnecessary to invoke "abrasive phenomena"1 to account for the absence of perikymata.

A. D. B. and D. Reid (manuscript in preparation) have made ground sections of 31 unworn modern human incisor teeth, selected for perikymata expression where possible, allowing counts to be made in imbricational enamel of surface striae ( \pm s.d.) in $\left(n_{\mathrm{s}}\right)$ teeth, and range, together with perikymata counts ( \pm s.d.) in $\left(n_{\mathrm{p}}\right)$ teeth:

$I_{1}:(10) 132 \pm 9.9,111-154 ;(7) 133 \pm 15.5$

$I_{2}:(6) 141 \pm 20.0,110-164 ;(4) 146 \pm 10.0$

$I^{1}:$ (7) $160 \pm 26.0,135-208 ;$ (4) $>74$

$\mathrm{I}^{2}:$ (8) $139 \pm 11.3,123-153 ;(7) 140 \pm 10.6$
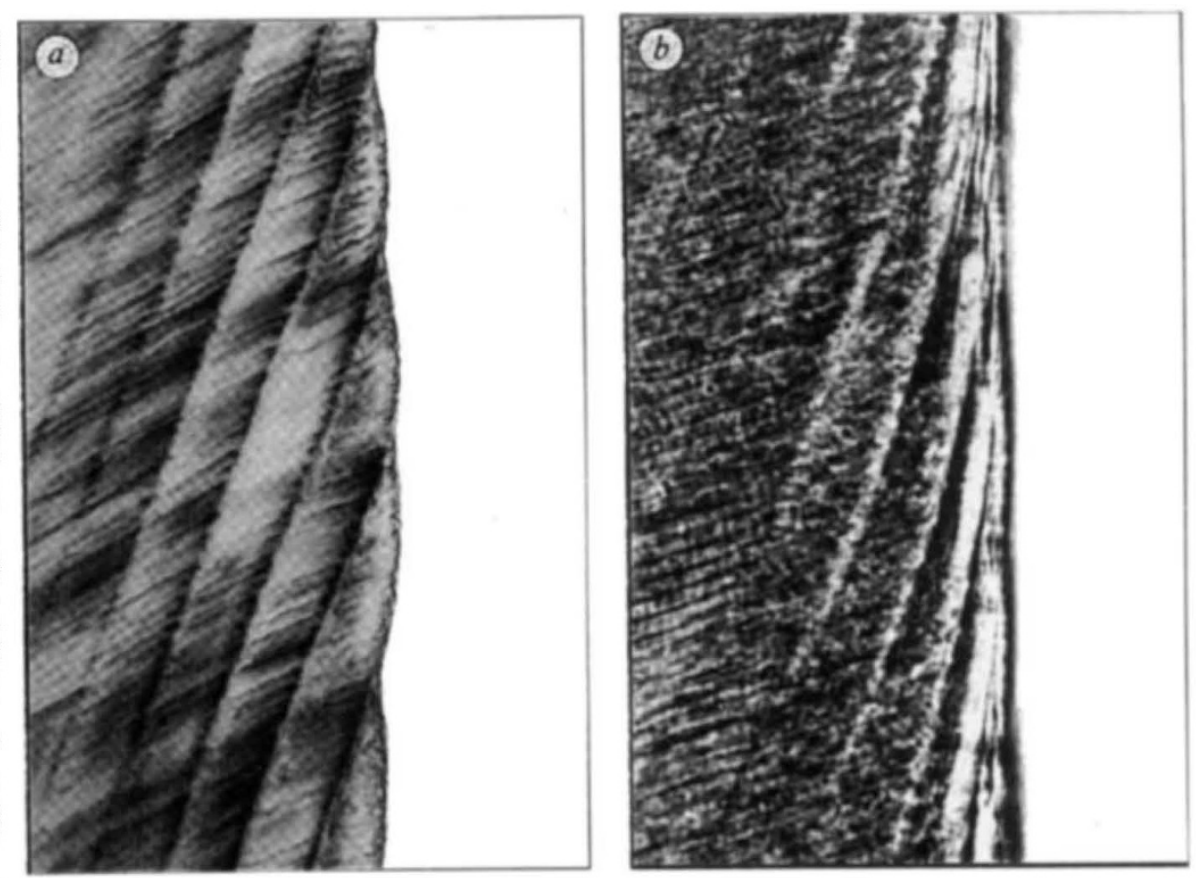

On the surface - demarcating perikymata $(a)$ and smooth enamel surface $(b)$.

Imbricational striae counts corresponded closely to perikymata counts in $I_{1}, I_{2}$, and $I^{2}$ and counts decreased in the series $\mathrm{I}^{1}>\mathrm{I}_{2}$, $>\mathrm{I}^{2}>\mathrm{I}_{1}$.

Perikymata are váriably expressed, and counts are reliable only in teeth showing a continuous series. $\mathrm{I}^{1}$ showed least consistency in perikymata expression, with no tooth showing a complete perikymata series from cervix to incisal edge. These results suggest that Mann et al.'s $I^{1}$ specimen is not expressing all of its subsurface striae, and should be excluded from further consideration. To establish the minimum chronological age of this individual, the tooth $\left(\mathrm{I}_{1}\right)$ with highest perikymata counts (157) must be used. Crown formation time is $3.5-3.9$ years $(7-8$ day periodicity and 0.5 yr buried increments). Age at death includes an interval between birth to onset of mineralization (estimated $0.25 \mathrm{yr}$ ), plus time to form $3 \mathrm{~mm}$ of root at a rate of $3.8-2.9$ (ref. 4) $\mu \mathrm{m} \mathrm{day}^{-1}$ (2.2-2.8 yr) giving an age at death of between 6 and $7 \mathrm{yr}$. This estimate is wholly consistent with the eruption status of M1, which erupts between 6 and $7 \mathrm{yr}$ in modern humans (against 2.2-3.7 yr) ${ }^{1}$.

We are acutely aware of the inconstant expression of perikymata, having studied all the several hundred available hominid teeth from Koobi Fora, Kenya; Olduvai Gorge, Tanzania and Sterkfontein, Kromdraai and Swartkrans in South Africa. Incisors without complete perikymata expression were excluded, leaving only nine Paranthropus, five Australopithecus, and four early Homo teeth. Mann et al. ${ }^{1}$ do not acknowledge differences in perikymata counts between gracile and robust australopithecines ${ }^{2,3}$. Mean Paranthropus (SK62 R and L; SK63; SK71; SK73; OH30; ER812; ER1477; ER1820) $I_{1}$ perikymata counts ${ }^{3}(n=9), 81 \pm 14.3$, are highly significantly smaller $(\mathrm{P}<0.0001)$ than our modern human $I_{1}$ sample cited above; and also Mann et al.'s ${ }^{1}$ combined incisor sample which includes low counts $(n=$ 12), $116 \pm 25(\mathrm{P}<0.004)$. Australopithecus(Sts24a; LH2; LH3 I ${ }^{1} \mathrm{I}^{2}$; LH6) combined incisor $^{3}$ counts $(n=5), 146.2 \pm 24.5$ are not significantly different from either modern human sample.

Apes have large teeth which take longer to form than modern man, yet erupt earlier, achieved by more rapid rates of root development ${ }^{5}$. Foreshortened growth periods in Australopithecus seem to be linked with faster root growth ${ }^{3}$. Smith has shown ${ }^{6}$ that the age of M1 eruption in primates is highly correlated $[r=0.98]$ with adult brain weight, suggesting ape-like M1 eruption times in early hominids. Both microanatomical and comparative evidence agree in suggesting rapid tooth formation, early eruption of teeth and short periods of growth and development in early hominids.

\section{A. D. BEYNON}

Department of Oral Biology,

The Dental School,

University of Newcastle-upon-Tyne, Newcastle-upon-Tyne NE2 4BW, UK M. C. DEAN

Department of Anatomy and

Developmental Biology,

University College,

Gower Street,

London WC1E 6BT, UK

1. Mann, A., Monge, J. \& Lampl M. Nature 348, 202 (1990) 2. Bromage, T. G. \& Dean, M. C. Nature 317, 525-527 (1985). 3. Beynon, A. D. \& Dean, M. C. Nature 335, 509-514 (1988) 4. Dean, M. C., Beynon, A. D. \& Reid, D. J. Am. J. phys. Anthrop. (in the press)

5. Beynon, A. D.. Dean, M. C. \& Reid, D. J. Am. J. phys. Anthrop. (in the press)

6. Smith, B. H. Evolution 43, 683-688 (1989).

- This correspondence is now closed Editor, Scientific Correspondence. 